\title{
Reflexões sobre questões metodológicas e práticas em pesquisas em educação
}

Bernardete Angelina Gatti

Pesquisadora da Fundação Carlos Chagas

\section{Resumo}

Comunicação apresentada no III Seminário de Epistemologia e Teorias da Educação e IV Colóquio de Epistemologia da Educação Física. Trata da problemática da identificação do campo relativo às pesquisas educacionais e suas relações com questões formativas.

Palavras-chave: Educação; Pesquisas Educacionais; Formação de Professores.

\section{Resumem}

Ponencia presentada em el III Seminário de Epistemología e Teorias de La Educación y IV Coloquio de Epistemología de la Educación Física. Trata de los problemas de la identificación del campo relativo a lãs investigaciones educacionales e sus relaciones com cuestiones formativas.

Palabras claves: Educación; Investigación para la Educación; La formación de Docentes. 
$\mathrm{P}$ elo contexto sócio-cultural que contemporaneamente se delineia, os estudos no campo da Educação estão cada vez mais submetidos a novas exigências de qualidade, até de excelência mesmo. Esse campo vem sendo pressionado por imperativos de ordem científica e de ordem profissional, como também de ordem política, administrativa e econômica, imperativos às vezes complementares, mas, muitas vezes contraditórios. As tensões criadas por essas pressões nem sempre são decodificadas e analisadas mais a fundo.

Vale perguntar, então, sobre conceitos utilizados para caracterizar o campo, distinções que podem clarificar significados e contribuir para sua auto-afirmação, sobre identidade e formas investigativas. A questão sobre se nossos interlocutores, especialistas de outros campos, estão compreendendo e podem articular os tipos de contribuições que estamos oferecendo com nossos estudos, não é algo periférico. Refere-se à consistência do campo investigativo em educação.

Há perguntas que precisam ser consideradas: de onde partimos? Com quais referentes? Para quem queremos falar? Por quê? Que tipos de dados nos apóiam?

Temos utilizado muitas vezes diversificados termos para significar uma mesma coisa, na dependência de posturas momentâneas. No Brasil optamos por usar em larga escala e com amplos significados a palavra educação. Não nos preocupamos, por exemplo, com distinguir educação em geral - fato social que permeia a sociedade como um todo e seus vários instituídos - de educação escolar - aquela que a escola provê. Na maior parte dos trabalhos publicados falamos desta última, porém sem qualificar isto, criando um espaço um tanto vago de entendimento para diversos interlocutores.

Fica colocada a questão da identificação um pouco mais clara do campo relativo às pesquisas educacionais, na medida em que se deseja, e também somos instados, a nos comunicar com diferentes setores sociais e setores acadêmicos, e, que é necessário que sejamos compreendidos, que nossos conhecimentos sejam bem interpretados e que tragam contribuições 
realmente relevantes. Para tanto precisamos nos preocupar com alguns aspectos básicos relativos à validade de nossos trabalhos de pesquisa.

\section{Campo de investigação}

A identificação do campo das pesquisas em educação tem sido objeto de análises mais intensas nos últimos anos. Três aspectos que interferem na identificação desse campo enquanto campo científico - campo de conhecimento com especificidades - bem como, quanto ao espaço que pode ocupar no âmbito das ciências humanas e sociais, merecem nossa consideração. São eles: o das denominações e conceitos utilizados, a própria idéia de campo e as questões de identidade e formas investigativas. Este último aspecto se liga aos caminhos da pesquisa em educação e às suas relações com questões formativas.

\section{Conceitos e autoafirmação do campo}

No contexto internacional, e especialmente entre autores europeus, está posto o debate sobre os termos utilizados para a qualificação de estudos no vasto campo que se denomina "educação", termos tais como pedagogia, ou ciências da educação, ou ciências do ensino, ou didática, etc., considerando-se que a forma e os contextos de emprego desses termos confundem interlocutores de outras áreas e os leigos, como também gestores, dificultando, muitas vezes, a delimitação de domínios e o clareamento de articulações, interfaces e transvariações com outros campos de conhecimento. Considera-se que autores adotam um dos termos sem que se tenha muita clareza do porque, ou, usam os termos como sinônimos, tornando, também, confusa ou ambígua sua qualificação disciplinar em currículos e programas de formação acadêmica. Questiona-se, então, o sentido de seus usos, suas abrangências, semelhanças e diferenças, e, sobre suas relações. A busca desses sentidos faz-se, não no intuito de impor uma unicidade de denominação, mas na direção de se tentar superar alguns conflitos que se instauram pelas preferências terminológicas entre os 
acadêmicos, como também para clarear algumas especifidades associadas a cada termo, o que pode permitir situar posições na investigação científica e colocar maior clareza para nossos interlocutores. É preciso, nessa ótica, cuidar de nossa linguagem conceitual e de nossas formas comunicativas sociais. (Mazzotti e Oliveira, 2000; Schurmans, 1998; Hofstetter, Schneuwly, Gretler, 2000). Ao preferirmos a expressão "pesquisa em educação", tout court, estamos sinalizando uma posição integradora, convergente de várias áreas, porém com um ponto de partida: os processos educativos. Preferindo "ciências da educação", sinalizamos um olhar que distingue vários campos de investigação em educação, separados e voltados a conhecimentos que se originam e se dirigem a outros campos, e, assim por diante. As expressões carregam significados. A consciência sobre esses significados, e a escolha de emprego de uma outra expressão a partir dessa consciência, representaria um passo na superação da alienação - ou da cooptação - com que expressamos pela linguagem nossos pensamentos.

Charlot (1998) defende que a concepção que temos das "ciências da educação" (sic), e particularmente de sua história, é nitidamente influenciada pela posição que se ocupa no campo e/ou por uma certa experiência (ou não experiência) em atividades de pesquisa em educação. Portanto, usar um termo ou outro (ciências da educação, ciências do ensino, pedagogia, didática, etc.) tem mais a ver com o histórico e a posição profissional dos que produzem no campo e menos a ver com os significados, a questão conceitual, em si. Certas ancoragens profissionais e disciplinares determinam a preferência pelo emprego ou do termo ciências da educação, ou ciências do ensino, bem como dos termos pedagogia ou didática. A questão é saber, mesmo com certa flexibilidade e extensibilidade, do quê se está falando, e por quê, quando se emprega um ou outro termo. $\mathrm{Na}$ interlocução intra-área e inter-áreas seria fator de consistência. Isto ajudaria a fortalecer o campo da educação no confronto com outros, e a qualificar melhor os debates e sua posição no âmbito das ciências sociais e humanas. Essa questão tem a ver com certa coerência de posições e de identidade. 
Tomemos os termos "pedagogia" e "didática". O que setores fortes, conceitualmente, das áreas humanas e sociais questionam é: de quê afinal estamos falando quando falamos de pedagogia ou quando falamos de didática, por exemplo. É comum encontrarmos nas publicações o uso desses termos como sinônimos.

Então, vejamos. O termo pedagogia tem sido usado com variações grandes de significado, indo desde abranger uma teoria educacional até a traduzir uma prática particular de ensino. É usual ouvir: "sua pedagogia não é boa.", quando se quer dizer "sua didática não é boa", ou "suas práticas de ensino não são boas" ou "sua técnica de ensino não é boa"... Nas falas do cotidiano talvez isto não seja de maior importância, porém na fala de educadores especialistas pode refletir, na interpretação de outros especialistas, a inconsistência da área, ou sua fragilidade conceitual/teórica. O termo didática também é empregado ambiguamente e, até certo ponto foi entre nós deixado meio à parte, tomado como aparentado a tecnicismo, ou como sendo um campo conceitualmente esvaziado.

Tomando os termos pedagogia e didática, tantas vezes empregados como sinônimos, verificamos que os estatutos da pedagogia e da didática constituíram-se de forma inter-relacionada, porém com sentidos diferentes, tendo sofrido metamorfoses determinadas por condições e contextos históricos da educação. Teóricos que se preocupam com a questão preferem distinguir uma expressão da outra. Segundo Lenoir (2000) pode-se admitir que essas duas áreas se constituem complementarmente na análise da relação ensino-aprendizagem, cada uma tratando dessas relações segundo tipos e níveis diferentes de abordagem.

Sobre o termo Pedagogia poderíamos nos situar com D. Hameline (1998) que, em texto denso e atual intitulado "Pedagogia", disseca a questão de seu significado, assumindo que "a pedagogia é a educação que pensa a si mesma, ou seja, que fala para si, se avalia e se imagina." A pedagogia seria o espaço das grandes reflexões em educação, das teorizações integrantes, o que a diferenciaria da área da Didática. Quanto ao termo Didática, ficamos com a posição de Oliveira e André (2003, p.1), segundo a 
qual este termo enuncia, em geral, a idéia de ação qualificada do ato de educar, vivências e reflexões de, sobre e para as relações educativas intencionais. Oliveira e André enfatizam que "a área de Didática constitui um campo de conhecimento sobre o ensino".

A pesquisa no âmbito da Pedagogia colocar-se-ia, assim, no contexto das teorias, como análise de fundamentos, de consequentes e de perspectivas, em vertentes filosóficas e epistemológicas de diferentes enfoques: idealista, funcionalista, pragmatista, empirista-lógico, hermenêutico, marxiano, fenomenológico, pós-moderno, etc. Aqui, o campo se mostra pelas diferentes vertentes construídas ao longo da história na tentativa de traduzir como o conhecimento humano-científico se constitui. Ele se fortalece e se afirma pelo domínio lógico-metodológico da vertente pela qual se envereda. Sobre este estatuto poucas reflexões e discussões se põem com clareza nos trabalhos e encontros de pesquisadores. Pouco se coloca na formação dos próprios educadores.

Já no que se refere à Didática levanta-se a necessidade de uma reflexão sobre a educação não apenas de natureza filosófico-epistemológica mas, também, praxiológica. Seria necessário discutir o escopo das práticas de ensino no âmbito da Didática.

Nem tudo se tranqüiliza com estas colocações, porém, elas podem balizar posições e pesquisas, e, sobretudo, domínios cognitivos. Seria desejável que a escolha de termos fosse mais consciente por parte dos pesquisadores, e mais claramente enunciada em certas análises. Seria desejável também que se refletisse mais vezes sobre essas denominações, perguntando se atendem a um estatuto epistemológico, ou a conveniências institucionais ou de nichos profissionais. É quase um imperativo para que o campo da pesquisa em educação se afirme e deixe de ser considerado "uma geléia geral", expressão jocosa que ouvimos de profissionais de outros campos ao se referirem aos termos pouco precisos, pouco explicitados, que os profissionais do campo da educação muitas vezes usam. Não é, pois, desprezível, a procura por melhor qualificação das áreas atinentes ao campo da pesquisa em educação, enquanto lugar de um conhecimento 
especializado, especialmente os relativos à Pedagogia e à Didática, com as sub-áreas decorrentes.

Educação como campo de conhecimento comporta a Pedagogia, como construção e reflexão, e comporta a Didática, como reflexão para e das ações educativas intencionais. Talvez seja necessário, de fato, maior cautela por parte de intelectuais e pesquisadores no uso desses termos, no sentido de se obter maior consistência para o campo de estudos em educação.

No Brasil, temos um elemento a mais que confunde um pouco mais a explicitação do termo Pedagogia. Como Pedagogia nomeia um curso de formação profissional de professores, a representação geral desse termo se mostra associada a aspectos curriculares e operacionais de formação de professores para os primeiros anos da educação básica introduzindo mais uma faceta, ou aresta, na construção da interface com campos de investigação em ciências humano-sociais que têm significados conceituais mais bem definidos (como a sociologia, ou a psicologia) que se apresentam como áreas de estudo com objetos e/ou processos em foco, mais claros. $\mathrm{O}$ termo Pedagogia, entre nós, mais geralmente associado a curso formativo de professores das séries iniciais, mostra-se nas representações, conceitualmente, distante de seu objeto tal como Hameline e outros teóricos discutem, com imagem diferente de campo específico de pesquisa e de estudos com foco claro. Tanto que, esse termo é pouquíssimo referido entre nós como área de estudos, havendo preferência neste sentido, pelo termo Educação; e, também, nas suas derivações, como a expressão "relações pedagógicas", ele significa relações de ensino (confundindo-se com didática e práticas de ensino).

Por outro lado, o termo Didática vem sendo substituído pela expressão Prática de Ensino, cada vez mais usado, especialmente em currículos escolares, deixando Didática para designar campo de estudos mais teóricos relativos às questões do ensinar - aprender, rarefazendo-se seu emprego, ficando as Práticas de Ensino como técnicas ou formas de ensinar bem específicas. Porém, nem sempre isto é clarificado nos estudos. 
Exercitar uma certa cobrança relativa a maior clareza conceitual não tem sido propriamente uma preocupação na área, entre nós. Porém, face às demandas científicas e sociais, estamos instados a refletir sobre nossos referentes e o significado dos termos que usamos nos contextos de trabalho que escolhemos. Como campo que trabalha também pela apropriação teórica do produzido em outros campos (como a filosofia, a sociologia, a antropologia, a lingüística, etc) a questão conceitual e de posição epistêmica torna-se problema central. No entanto, nem sempre as fontes de referência originais têm seu campo conceitual tratado com adequação, pertinência e fineza teórica.

A linguagem é viva. Muda. Significados mudam. As reflexões acima podem parecer desnecessárias para muitos, serem consideradas perfumaria para outros. Porém cabe pontuar que temos sido descuidados nas teorizações e conceitos, na colocação clara de nosso objeto e/ou problemas, e, cabe lembrar que a não distinção conceitual que vem caracterizando os estudos no campo da educação vem provocando dificuldades comunicacionais e interpretativas nesse campo de investigação, bem como na interlocução com outros campos, e nos contextos sócio-políticos, com prejuízos quanto à atribuição de relevância aos seus estudos.

\section{Idéia de campo de conhecimento}

Estudos que revelam a diversidade disciplinar quando se trata do campo da educação, nos fazem levantar a questão da multiplicidade de abordagens, mas também, de qual é a especificidade associada ao campo e de sua circunscrição no domínio das ciências humanas e sociais. Há sempre um questionamento, especialmente de cientistas sociais e profissionais da filosofia, sobre o estatuto da educação como campo de conhecimento. Pergunta-se se há um domínio específico desse campo ou um domínio que assegure de alguma forma sua unidade (fatos, teorias, postulados, etc) permitindo-lhe, face a outros campos de estudo, conservar uma certa especificidade, tendo a possibilidade de integrar a multiplicidade das disciplinas anexas que o próprio campo cria (Tenorth, 1998, p.140). 
A organização conceitual e institucional do campo de pesquisa em educação e suas relações e articulações com outros campos, no contexto das tensões tanto de ordem científica quanto das práticas profissionais a ele associadas, emerge contemporaneamente como uma necessidade, pelo risco da dispersividade e da conseqüente desconsideração dos demais campos nas ciências humanas e sociais, com os quais se confronta, ao mesmo tempo que se interliga. Para os que se colocam dentro do campo educacional nem sempre estes questionamentos são levados em conta, mas no concerto das políticas científicas e das políticas tecnológicas, bem como das políticas de ensino, especialmente das políticas de formação de professores, a força do campo ou a sua fraqueza tem a ver com seu impacto e relevância. Essa afirmação dos estudos em educação pode vir pela sua segurança conceitual, que a nosso ver, se constitui na interdisciplinaridade. Não se trata de assumir uma unidade de campo como homogeneidade, mas uma unidade de propósitos com clareza de abrangência e de estruturas conceituais. Trata-se da aquisição pelo campo de estudos em educação de uma caracterização mais clara enquanto campo acadêmico e investigativo, mesmo mantendo seu referencial plural.

\section{Identidade e formas investigativas}

Pergunta-se também pela identidade, pelas formas investigativas e pela relação com as demandas sociais, das investigações que podem ser colocadas no guarda-chuva da educação, esta tomada como amplo campo disciplinar. Muitos campos têm estudos que podem ser tomados como pesquisa em educação, e, não somente os associados a disciplinas específicas como pedagogia e didática, ou ao rótulo genérico de "ciências da educação", ou "ciências do ensino". Há uma vasta gama de estudos sobre e para a educação em variados campos do conhecimento tornando difícil assumir-se epistemologicamente um eixo identitário. Há estudos que podem ser qualificados como de educação, por exemplo, no campo da lingüística, no dos estudos da comunicação e da informação, na semiótica, nas neurociências, etc. Publicações se debruçam sobre essas questões e a 
multiplicidade de possibilidades e olhares mostra o que se pode chamar de uma "disciplina indisciplinada" (Hofstetter, Schneuwly, Gretler, 2000, p.26).

Resta-nos, então, considerar neste âmbito, questões do tipo: como colocamos nossos problemas de investigação? O que é uma questão que pode sem dúvida ser qualificada como de pesquisa em educação? Qual nosso foco? Então, temos que pensar o que constitui uma ótica propriamente educacional, portanto considerar de onde partimos e onde queremos chegar. A educação é o ponto de partida e de chegada? Coloca-se aqui o conflito entre uma ótica propriamente de educação (como campo investigativo) e óticas pertinentes a outros campos. Coloca-se também, como utilizar-se da interdisciplinaridade/transdisciplinaridade mantendo o foco do campo da educação.

Em estudo amplo realizado sobre a pesquisa em educação na França, cujas análises e reflexões nos parecem pertinentes de modo geral para outros países, Beillerot (2000) pontua três aspectos que merecem atenção: o primeiro, é, justamente, o fato que se encontra uma "grande complexidade de discursos e de explorações em relação à educação e à formação. Entre os extremos, por exemplo um grande levantamento macroscópico da economia dos sistemas escolares e a observação da ação educativa cotidiana de uma mãe em relação a seu bebê, há uma multiplicidade de situações, de dados, de práticas para as quais, sem dúvida, no momento, é vã a tentativa de querer ou de esperar que elas se juntem todas sob um único rótulo [...]"(p.158).

$\mathrm{O}$ segundo aspecto diz respeito às maneiras de proceder nas pesquisas. Esse autor encontrou uma grande gama de formas de coleta e relato de dados e fatos em estudos, desde a pesquisa mais ao estilo jornalístico até aos ensaios, passando por pesquisas que buscam a produção de dados e a investigação empírica problematizada.

Em terceiro lugar, coloca o aspecto relativo à relação pesquisa e demanda social. O discurso de que as pesquisas devem responder às demandas sociais é presente tanto no meio acadêmico, como em segmentos 
sociais que conseguem de alguma forma "ter voz". Beillerot (op.cit.) considera que, mesmo sendo a idéia de demanda social muito sugestiva, resta a questão de discernir com clareza o que é uma demanda social, quem a exprime, porquê, para quem, quando, para quê. Segundo ele, em educação, como em outras práticas, os indicadores de demandas são muito claros em alguns casos, mas, em outros casos são bem mais aleatórios. No primeiro grupo estariam as demandas que tomam a forma de plataformas descritas e solicitadas pelos legisladores, ou pelos executivos, pelas diferentes instâncias de gestão. O segundo grupo de indicadores de demanda social, seria representado notadamente pelas diferentes formas de mídia que dão voz a agentes sociais diversos (mandatários ou não) e que dão forma, a partir de informações triadas, selecionadas, ao que as clientelas ou as ideologias têm necessidade de dizer, como sendo sua opinião própria, suas reivindicações. Aqui toda demanda social é flutuante, sujeita aos modismos, a grupos hegemônicos eventuais. Assim, “o que se tem na realidade é que os debates com argumentos fortes, de boa fé, e fundamentados são raros. O que é chamado de demanda social está mais sujeito à paixão e à ideologia do que à razão. Isto faz com que os estudos e as pesquisas progridam muito pouco." Pode-se dizer que as demandas sociais, assim "produzidas", não se dirigem à construção científica (amplamente entendida) da educação propriamente, mas a outras instâncias, sobretudo as de poder, como crítica ou reivindicação, o que gera o risco de não se ultrapassar, dentro do campo investigativo em educação, a produção de "auto demandas sociais" como expressão de desejos internos, não escapando "às quimeras do corporativismo e do messianismo reunidos." (Beillerot, 2000, p.159). Estas posturas comprometem o campo, enquanto campo investigativo que deve avançar com perspectivas de genericidade, nos termos de Heller, ou seja, um pouco menos alienadas, que não sejam totalmente fruto de pressões ou desejos de domínio ou projeção, ou imposição de idéias e valores de um grupo hegemônico.

Considerando essas questões, pode-se afirmar que, do lado dos pesquisadores, há necessidade de um exame sereno da questão da "demanda 
social", que pode ser feita no confronto dos dois indicadores de demanda apontados acima, mais o conhecimento acumulado através de investigações confiáveis que já compõem o campo de saberes em educação e em suas áreas específicas. É nas sínteses possíveis, a partir de análises desses contrapontos, que a pesquisa educacional poderá avançar e produzir conhecimentos mais pertinentes e referenciais mais confiáveis, não ficando ao sabor de circunstâncias ou da superficialidade com que questões são postas nessas demandas, ou a partir delas. Trata-se aqui da consistência na construção dos problemas do campo educacional.

Dois pontos importantes restam a considerar. O primeiro, diz respeito à dúvida quanto a se as posições que esse debate instaura pelos estudos, artigos, congressos, serão não somente percebidas, mas, levadas em conta nas atividades dos pesquisadores, no futuro. O debate dessas questões é pertinente e importante para o contexto histórico atual e tem consequiências para as perspectivas epistemológicas e políticas do campo - para o aspecto de sua valorização e de sua posição no contexto social, político, e no contexto científico. Como coloca Charlot (1998), os atores do campo disciplinar, especialistas de diversos domínios, serão capazes de superar uma visão estreita, individualista, concorrencial, muito dependente do contexto político ou institucional do momento? As questões corporativistas e ideológicas implicadas na produção, disseminação e utilização dos conhecimentos serão olhadas e analisadas de modo mais conseqüente? Ou ainda, podemos perguntar se no campo da educação se pode apostar que a análise, a pesquisa e a reflexão vão fortalecer o campo e transformar a ação?

$\mathrm{O}$ segundo ponto diz respeito às características e nuances da identidade do campo e de seus estudos, identidade pensada como uma topologia de metamorfose, na composição de diversidades, na produção de um saber válido, legitimado tanto pela comunidade científica como pelas comunidades outras de referência e a sociedade em geral. Identidade e legitimidade construídas num processo transacional de cooperação conflituosa, na expressão de Schurmans (1998), porém na busca de consistência analítica e comunicativa. O termo Educação, designando um 
campo de estudos e um campo de ação, acaba por traduzir o hibridismo em que suas representações e conceitos estão embebidos. Porém, evoca uma abrangência que pode ser abertura salutar, mas, que exige distinções claras quanto a que se está referindo em um estudo e de que forma o investigador aborda seu problema.

\section{Educação: campo de pesquisa}

Apoiando-nos em Lenoir (2000) e Bronckart (1989), pode-se relatar quatro grupos de concepções associadas aos estudos em Educação, como campo investigativo que tem por objeto ações educacionais, na perspectiva de um recorte para olhar essas ações em sua colocação nas realidades sociais e escolares. Essas concepções se refletem diretamente nas pesquisas desenvolvidas e nos modos de conceber a educação.

As concepções destacadas se entrelaçam com várias formas e caminhos possíveis para colher e trabalhar dados em investigações no que se refere às situações de ensino e de aprendizagem escolar, ou, a processos formativos de diferentes naturezas e níveis (por exemplo, a formação básica de professores, ou a continuada, a formação de técnicos ou especialistas, a formação dos jovens, etc), a processos de gestão. Geram formas diferentes no desenvolvimento das pesquisas.

A primeira concepção está associada a uma perspectiva técnicoinstrumental, a educação sendo vista como "ciência de procedimentos", como conjunto de métodos, técnicas e procedimentos para o ensino, portanto na aproximação da didática, e a ordenações organizacionais e de gestão. Esta concepção tem objetivos prescritivos, normativos ou sugestivos, nos quais a perspectiva comportamental é seu prolongamento.

Um dos caminhos mais comuns para a investigação de problemas nessa concepção é pelo recorte específico de disciplinas de referência, como a psicologia, a história, a biologia, a sociologia, a filosofia, etc, com grande predomínio das perspectivas da psicologia do desenvolvimento. $\mathrm{O}$ foco 
nasce fora das teorias educacionais, advindo de áreas contributivas ao olhar da pesquisa com educação.

A segunda concepção está associada à perspectiva lógico-cognitiva, tendo como foco as teorizações sobre questões associadas ao ensino das disciplinas. A proposição é de que se diferencie pesquisa de ensino, não devendo a pesquisa conduzir diretamente a recomendações de ações na escola, pelo menos não antes de se ter racionalmente estabelecido parâmetros epistemológicos seguros para conteúdos em suas especificidades disciplinares. Centra-se, então, sobre conteúdos de saber, sobre as bases epistemológicas desses conteúdos - os de cada disciplina. Esta concepção estaria, segundo Bronckart (op.cit.), associada a uma "segunda geração" de pesquisadores que investiga as relações ensino-aprendizagem, analisando o estatuto dos saberes a ensinar e sua adequação às características sóciocognitivas dos alunos, as interações entre os alunos, o "contrato didático", mas, sem questionar o significado, a necessidade e suficiência desses saberes e seu processo de objetivação sócio-histórica. Seria uma concepção cujo foco é o desvelamento de processos intrínsecos ao binômio ensinoaprendizagem.

Outra aproximação encontrada é a feita através de disciplinas científicas diversificadas. No caso de se ter como ponto de partida as disciplinas científicas básicas - tipo álgebra, geometria, física teórica, genética, teorias da comunicação, literatura, lingüística, tecnologias, etc trabalha-se com a produção, aplicação, articulação e conceitualização de conhecimentos. Privilegia-se o pólo objeto e a lógica dos conhecimentos em área ou sub-área específicas.

Ainda, há as aproximações que têm como ponto de referência as disciplinas escolares propriamente ditas (português, matemática, ciências, educação física, inglês, história, geografia, artes, etc.) em que se tem como foco as questões de transmissão, apropriação e reprodução de conhecimentos selecionados, em geral, estruturados conforme os conteúdos de uma proposta curricular. O foco aqui é o aluno, e a lógica da aprendizagem escolar do aluno. 
A terceira concepção coloca-se do ponto de vista do sujeito que aprende, investigando os processos de apropriação de saberes e se apóia em teorias que têm origem principalmente nas teorias de gênese de referência piagetiana, ou de referência sócio-interacionista ou sócio-histórica, de diferentes vertentes, não havendo preocupação explícita com as bases epistemológicas que sustentam os conteúdos do ensino. $\mathrm{O}$ foco são os processos de aprendizagem das crianças ou jovens, gerando o que se poderia caracterizar como uma abordagem cognitivista, em que os sujeitos aprendentes são o foco, não o que há para aprender ou o que se considera desejável que aprenda em determinada sociedade por razões históricas. Não há um olhar sobre o valor dos conteúdos dos saberes em situações sociais determinadas. Apenas o processo do aprender é considerado.

O segundo e o terceiro conjunto de estudos trazem contribuições ricas para a compreensão de aspectos específicos das situações de ensino e de aprendizagem. Porém, se de um lado considera-se a contribuição das pesquisas sobre processos de ensino como dando um aporte às práticas educacionais em segmentos específicos do conhecimento (aquisição da leitura e escrita - a partir de teorias lingüísticas, apenas -; ensino da matemática, pela lógica matemática, ou por teorias de aprendizagem, e outras), de outro, fazem-se críticas a essas contribuições, que são consideradas restritas e na maioria dos casos descontextualizadas. Bayer e Ducrey (1998) são duros em suas críticas e as caracterizam como uma aproximação reducionista, pois enfocam apenas um dos ângulos das situações de ensino, transparecendo nessas pesquisas, em muitos casos, "ingenuidades, simplismos, não consideração dos múltiplos fatores em jogo, em diferentes níveis, nas situações de ensino".

A quarta concepção é marcada por uma praxiologia, na vertente de um pensamento de tendência mais formativa e, voltada à ação. Parte do pensar as ações educativas criando conceitos fecundos na relação práticasteoria e produzindo conjuntos instrumentais ancorados em uma reflexão sobre suas utilizações e suas finalidades, em contextos complexamente considerados. Segundo M. Develay, em citação feita por Lenoir (2000, p. 
188), esta posição pode se exprimir pela afirmação de Henri Wallon: "A teoria nasce da prática e deve a ela retornar.", no que o autor completa que se pode dizer que conhecimento em educação nasce da e com a prática e deve aí retornar, desde que se faça uma construção axiológica. Sem o retorno à prática e sem a passagem pela axiologia, o conhecimento se arrisca a ser apenas um "simulacro." Nesta vertente a pesquisa é concebida sobretudo como pesquisa-ação, em variadas possibilidades, procurando assegurar uma interrelação entre a pesquisa formal e os procedimentos da investigação na e/ou com a ação, porém, criando teorizações e fundamentando-as. Mobilizam-se certos conhecimentos para compreender situações e inferir/criar novos modos de ação. Funda-se sobre a análise do estatuto sócio-histórico do saber a ser ensinado e dos objetivos do próprio ensino, considerando critérios de pertinência e não critérios de legitimidade. Conforme, ainda Lenoir (2000, p.189), nesta posição, a pesquisa parte dos resultados de uma "análise crítica do contexto social e da situação real na qual o ensino de uma matéria escolar se atualiza. A questão da produção de coerência orientada para a ação, assim como da contextualização social se tornam centrais". Importante é assinalar aqui que se assume a inter-relação e a interação indispensáveis entre os processos de ensinar, os de aprender, os sentidos dos conteúdos e os processos de formar. Incorporam-se tendências das perspectivas culturalistas e as da chamada "nova sociologia".

Despontam aqui pesquisas que têm uma abordagem interacional, na qual se procura considerar todas as relações entre os conjuntos de diferentes fatores pertinentes às questões ligadas às ações educacionais: aluno, professor, conhecimento, situação, contexto.

Surge, também, a abordagem biográfica, tanto os estudos autobiográficos, como os realizados por um interlocutor (pesquisador), com o objetivo de compreender os processos formativos individuais, os quais vêm se colocando como um espaço para a investigação em diferentes questões das relações escolares. Cifali (1998) e Dominicé (1998) discutindo a prática (uma prática) como objeto de pesquisa e como lugar legítimo de produção de conhecimento científico, colocam a necessidade de uma objetividade que 
é conquistada por um trabalho sobre a própria subjetividade pela intersubjetividade que se pode criar com vários interlocutores. Porém, tem sido lembrada a necessidade, para esses estudos, de um enquadramento teórico e metodológico mais aprofundados e com maior especificidade, o que lhes falta de modo geral. Muitos destes trabalhos parecem monólogos, ou são descritivos, com apelos emotivos, faltando-lhes interpretações coerentes, inferências cognitivas que avancem compreensões. Esses estudos chamam por aspectos da pesquisa clínica, com suas qualidades e limites, por exemplo, demandam cuidados especiais com a questão da subjetividade e dos controles. A face clínica da pesquisa com base em biografia é clara, mas lembremos que, a fala, ou o texto refletido de uma experiência, o solilóquio, só pode permitir a construção/reconstrução de conhecimento desde que se ancore em uma ótica referencial (seja ela antecedente ou emergente no processo), considerando-se, como na clínica que, "falar sobre" e "falar com" é um bom meio de tomar consciência. Mas, na pesquisa há alguns passos além, por exemplo, o do interpretar teorizando, o do atribuir significado alargado, o da comparação, o da confrontação com outros conhecimentos e informações fornecidos pela literatura especializada, mesmo que de caráter idiossincrático.

Ao trazermos acima algumas análises críticas, lembramos que pode-se distinguir estudos que se situam no eixo de uma aproximação epistemológica que leva ao questionamento de conceitos, das formas de pensar os problemas. Nesta aproximação análises críticas são feitas aos trabalhos de pesquisa tal como realizados. Por exemplo, fazendo a crítica às análises binárias, com exclusão de múltiplos fatores (aluno-professor; formador/aprendente; saber/aluno; saber/professor, etc.). Ou, à excessiva psicologização, quando a referência especial é o indivíduo; ou às tendências excessivamente sociologizantes, em que se privilegia, sobretudo, o contexto, desaparecendo os sujeitos em ação; ou ao extremo empirismo, vinculandose todo conhecimento somente na experiência; ou ainda as análises críticas às aproximações disciplinarizantes em excesso, que são excessivamente programáticas, portanto, centrando-se rigidamente no saber dos especialistas 
e das especialidades disciplinares. (Lenoir e Gagnon, 1995; Lenoir, 2000). Todos esses ângulos têm sido criticamente examinados na perspectiva epistemológica no campo da educação, em visão epistemológica mas também praxiológica, e essa abordagem investigativa se mostra como uma espécie de referência crítica, de meta-análise, que levanta questões sobre o que se pensa, como se pensa, como se problematiza e o que se faz na pesquisa em educação. Seu papel de explicitação crítica é fundamental para o avanço dos conhecimentos.

\section{Concepções na pesquisa em educação e formação de professores}

Quando se pesquisam ações educacionais, seja sob que perspectiva for, dever-se-ia ter sempre no horizonte a questão da formação de quem vai formar, e também de quem está formando. Por essa razão é importante discutir a relação dessas abordagens e as investigações delas decorrentes, com a formação dos professores, seja a sua formação básica seja a formação continuada. O professor é "um" ausente em muitos dos estudos sobre ações educacionais, como se pode ver nos três primeiros eixos de concepções presentes na pesquisa em educação.

$\mathrm{O}$ aspecto formação dos professores nem sempre se faz presente nas preocupações dos pesquisadores quando tratam do ensino ou das aprendizagens, os quais, voltados a seus focos específicos de estudo, deixam de refletir sobre as relações de suas concepções e resultados analíticos com as questões formativas dos professores, não se considerando que o conhecimento que se produz nos estudos institui formas de pensar e representar, guiando o agir. Estas formas atuam nos processos de formação pré-serviço e na formação continuada, seja a desenvolvida de modo formal ou informal, e, de uma forma ou outra impactam as práticas.

Podemos considerar, simplificadamente, que as relações educacionais, particularizando para o ensino, envolvem cinco pólos: o aluno, o professor, o conteúdo, o contexto de referência (formas de teorização) e o contexto de trabalho (em certo contexto social). Cada um desses cinco pólos são complexos em sua constituição, complexidade esta que se reflete nas 
relações entre eles na situação concreta das escolas. Para exemplificar essa complexidade, tomemos o polo "aluno"; ele congrega fatores como condição sócio-econômica e cultural do próprio aluno, tipo de família e de relações familiares, formas educativas na família, relações de vizinhança, especificidades cognitivas, acervo cognitivo, constituição emocional, aspectos de saúde, lazeres, motivações, etc, etc. A concretude dos atores e fatores presentes na situação escolar nem sempre é trazida à luz, tratando-se, por exemplo, o educando, ou o professor, como uma vaga abstração, um ser universal despessoalizado e descontextualizado.

Considerando os processos formativos de professores, que são também processos de formação identitária profissional, se estudos privilegiam apenas um dos pólos, é esse polo que tomará espaço nas atitudes e ações docentes. Assim, se se privilegia apenas as disciplinas de referência, uma vez que estas geram estudos e pesquisas que têm o recorte específico de outros campos, acaba-se por enfatizar na formação apenas aspectos desses campos, sejam os filosóficos, ou os sociológicos, ou os psicológicos, etc., a partir de uma reflexão que se restringe aos mesmos, dentro de seus interesses internos. O problema não está nos recortes disciplinares, mas, em serem tomados não como recortes parciais mas como "o conhecimento" em educação. Ao enfatizar este ângulo, outros deixam de ser considerados, ou são excessivamente minimizados. Esta limitação ocorre na formação de professores, como na pesquisa sobre ela, quando qualquer um dos fatores intervenientes é tomado como referência sem interrelacioná-lo com os demais. Pode-se, por exemplo, voltar-se apenas para a lógica da aprendizagem, reduzindo a compreensão do aluno aos processos cognitivos, ou, enfatizar a lógica dos saberes, dando ênfase à lógica disciplinar dos conteúdos, deixando de lado outras condições importantes na situação de ensino. Nestes dois casos os sujeitos sociais concretos ficam ausentes, pensando-os como sujeitos homogêneos, desconsiderando os avatares do cotidiano relacional de professores e alunos, o instituído escolar como corpo sócio-antropológico. Deixando de lado questões que dizem respeito à 
comunicação humana, a construção do imagético, dos valores, das representações.

A pesquisa na concepção inter-relacional tenta considerar todos os ângulos da situação em suas relações, mesmo escolhendo focos delimitados, e selecionando alguns dos fatores, pela dificuldade, ou até impossibilidade, de considerar todo o conjunto e suas combinações, interdependências e transvariações. Nesta perspectiva há teorizações emergentes, fundadas em epistemologias da práxis. Os processos formativos orientados por este enfoque procuram enfatizar a totalidade situacional de um contexto educativo, por exemplo, da escola e do ensino, da sala de aula, na interrelação de diferentes componentes, integrando perspectivas sócioantropo - psicológicas.

Essas considerações têm por objetivo assinalar a necessidade de maior clareza na exposição do âmbito de uma pesquisa e seus limites no campo de conhecimento, o que demanda um olhar abrangente do campo por parte do pesquisador intérprete de processos educacionais. Recortes para estudos são necessários, porém a consciência de que se recorta, como, porquê, para quê, não pode ser anuviada, ou banida por visões parciais de certezas pré-postas.

\section{Referências}

BAYER, E., DUCREY, F. Une éventuelle science de l'enseignement aurait-elle sa place em sciences de l'éducation ? In : HOFSTETTER, R., SCHNEUWLY, B. (ed.) Le pari des sciences de l'éducation. Raisons éducatives, 98 : 1-2, ParisBruxelles, De Boeck Université, 1998.

BEILLEROT, J. La recherche em éducation em France: résultats d'enquêtes sur les centres de recherches et les périodiques. Revue Suisse des sciences de l'éducation, $\mathrm{n}^{\circ} 1,22^{\circ}$ Année, Fribourg, Suisse, 2000, p.145 - 163.

BRONCKART, J. P. Du statut des didactiques des matières scolaires. Langue Française, $\mathrm{n}^{\mathrm{o}}$ 82, p.53- 63.

CIFALI, M. Clinique et écriture : une influence de la psychanalyse dans les sciences de l'éducation. In : HOFSTETTER, R.,SCHNEUWLY, B. (ed.) Le pari des sciences de l'éducation. Raisons éducatives, 98 : 1-2, Paris-Bruxelles, De Boeck Université, 1998. 
CHARLOT, B. Les sciences de l'éducation en France:une discipline apaisée, une culture commune, un front de recherche incertain. In : HOFSTETTER, R.,SCHNEUWLY, B. (ed.) Le pari des sciences de l'éducation. Raisons éducatives, 98 : 1-2, Paris-Bruxelles, De Boeck Université, 1998.

DOMINICÉ, P. La contribution de l'approche biographique à la connaissance de la formation. In : HOFSTETTER, R.,SCHNEUWLY, B. (ed.) Le pari des sciences de l'éducation. Raisons éducatives, 98 : 1-2, Paris-Bruxelles, De Boeck Université, 1998.

HAMELINE, D. «Pédagogie ». In : HOFSTETTER, R.,SCHNEUWLY, B. (ed.) Le pari des sciences de l'éducation. Raisons éducatives, 98 : 1-2, ParisBruxelles, De Boeck Université, 1998.

HOFSTETTER, R.; SCHNEUWLY, B.; GRETLER, A. Les sciences de l'éducation dans un contexte en mutation. Revue Suisse des sciences de l'éducation, $\mathrm{n}^{\circ}$ 1, $22^{\circ}$ Année, Fribourg, Suisse, 2000, p. 5 - 14.

LENOIR, Y. La recherche dans le champ des didactiques: quelques remarques sur les types de recherche, leur pertinance et leur limites pour la formation à l'enseignement. Revue Suisse des sciences de l'éducation, $\mathrm{n}^{\circ}$ 1, $22^{\circ}$ Année, Fribourg, Suisse, 2000, p.177 - 220 .

LENOIR, Y.; GAGNON, S. La didactique dans la formation des maitres au Québec : une mise en perspective. In :ANDRÈS, F.F.,et al.(ed.) La escuela que vivimos. Universidad de León, León, 1995, p.193 - 225.

MAZZOTTI, T. B., OLIVEIRA, R. J. de. Ciência(s) da educação. Rio de Janeiro, DP\&A, 2000.

OLIVEIRA, M. R. N.S., ANDRÉ, M. E.D.A. A prática do ensino de didática no Brasil: introduzindo a temática. Pedagogia Cidadã: Cadernos de Formação. São Paulo - SP: UNESP, Pró-Reitoria de Graduação, 2003.

SCHURMANS, M. N. Les sciences de l'éducation : fantôme, agrégat, prototype ou idéal-type ? In : HOFSTETTER, R.,SCHNEUWLY, B. (ed.) Le pari des sciences de l'éducation. Raisons éducatives, 98 : 1-2, Paris-Bruxelles, De Boeck Université, 1998.

TENORTH, H. E. Les sciences de l'éducation em Allemagne. Un cheminement vers la modernité entre science, profession enseignante et politique. In : HOFSTETTER, R.,SCHNEUWLY, B. (ed.) Le pari des sciences de l'éducation. Raisons éducatives, 98 : 1-2, Paris-Bruxelles, De Boeck Université, 1998. 